\title{
OMISSÃO DE IMPUGNAÇÃO DAS RAZÕES ESSENCIAIS E USO META- ARGUMENTATIVO AVALIATIVO DAS RAZÕES ACESSÓRIAS NAS SENTENÇAS DA SUPREMA CORTE DE BUENOS AIRES ${ }^{i}$
}

Mariana Cucatto

Resumo: Na argumentação jurisdicional é possível diferenciar entre os argumentos essenciais ou dirimentes que sustentam uma sentença -ratio decidendi-,e os não dirimentes -acessórios ("a mayor abundamiento")-. Partindo da perspectiva teóricometodológica da Linguística Cognitiva, este artigo descreve e explica, a partir da análise de dois precedentes, como a Suprema Corte de Buenos Aires, mediante o uso metaargumentativo avaliativo das razões acessórias, recusa recursos que apenas têm por objetivo as razões não dirimentes, omitindo atacar as razões essenciais da decisão recorrida. Esse uso meta-argumentativo permite constatar de que modo este organismo superior do Poder Judicial da província de Buenos Aires exerce uma função didática, enquanto ensina como diferenciar entre os argumentos dirimentes dos que não são, como devem ser utilizados os argumentos não dirimentes e como deve ser idoneamente atacada uma decisão judicial que contém argumentos dirimentes e outros que não são.

Palavras-chave: Argumento essencial. Acessório (a mayor abundamiento). Função didática.

Abstract: In court argumentation, distinction can be made between those arguments which are essential or on which a decision is founded -ratio decidendi or holding-, and those which are not necessary to the result -further arguments (" a mayor abundamiento") or dicta-. This paper describes and explains, from a Cognitive Linguistic theoretical and methodological stance, how the Supreme Court of the Province of Buenos Aires dismisses those appeals which solely object further arguments and fail to attack the essential arguments on which the appealed decision is grounded, through the meta-argumentative evaluative use of further arguments. Such meta-cognitive use allows us to see the way in which the highest court in the Province of Buenos Aires plays a teaching role by showing how to distinguish between essential arguments from those which are not and how a judicial decision containing both essential and further arguments must be properly attacked.

Keywords: Essential argument. Further arguments ("a mayor abundamiento"). Teaching role.

\footnotetext{
${ }^{i} \mathrm{NT}$ : Em português, não existe uma terminologia específica equivalente à expressão em espanhol $a$ mayor abundamiento, utilizada, neste artigo, para se referir aos argumentos obiter dicta. Profissionais de Direito aqui consultados sugeririam o uso do termo acessório, que foi, então, adotado nesta tradução.

ii Doutora em Letras, Professora Titular da Universidad Nacional de La Plata (UNLP) e Pesquisadora do Consejo Nacional de Investigaciones Científicas y Técnicas (CONICET), Argentina. E-mail:marianacucatto@yahoo.com.ar.
} 
EID\&A - Revista Eletrônica de Estudos Integrados em Discurso e Argumentação, Ilhéus, n. 14, jul/dez.2017.

\section{Introdução}

No discurso jurisdicional, os argumentos acessórios são aquelas razões secundárias ou colaterais que não são dirimentes do caso, isto é, que não fazem parte das razões essenciais - o ratio decidendi - nas quais está fundamentada uma decisão judicial. O propósito deste trabalho consiste em estudar o que chamamos de uso meta-argumentativo avaliativo das razões acessórias, em dois casos extraídos de um corpus de sentenças pronunciadas pela Suprema Corte de Buenos Aires, Argentina - de agora em diante, SCBA -, a partir da perspectiva teórico-metodológica da Linguística Cognitiva'. Entendemos por uso meta-argumentativo avaliativo quando a SCBA, ao mesmo tempo em que fundamenta uma decisão - ao resolver sobre um recurso apresentado pelas partes contra a sentença de um tribunal inferior -, examina e avalia as razões acessórias utilizadas na sentença impugnada, à luz do questionamento realizado por ele ou pelo(s) recorrente(s).

Além disso, procuramos mostrar que nem sempre estão bem traçados os limites que separam os argumentos dirimentes dos argumentos acessórios e que essa confusão de limites pode comprometer os elementos que fundamentam o recurso e afetar sua eficácia impugnativa. É que o recurso poderá ser considerado infundado e fracassará, se nada mais impugnar os argumentos acessórios, mas mantém de pé, firmes e inquestionáveis, os argumentos dirimentes. Precisamente, neste artigo, são analisados dois precedentes nos quais a SCBA recusa os recursos onde apenas são atacados os argumentos acessórios, mas se omite de questionar os dirimentes, por resultar confusos ou estarem mal estabelecidos os limites que separam uns dos outros. Para realizar esta tarefa, são estabelecidas relações entre: 1) o grau de "prototipicidade" ou esquematicidade argumentativa que se evidencia entre as considerações essenciais ou dirimentes que conformam a ratio decidendi e as não dirimentes incluídas acessórias; 2) o ordenamento, o deslocamento e a omissão de questões, e de argumentos - essenciais e acessórias - por parte dos juízes e dos recorrentes.

Tentamos descrever e explicar como a SCBA, através do mencionado uso meta-argumentativo avaliativo das razões acessórias, amplia sua função jurisdicional em direção a outra função não jurisdicional: a função didática.

\footnotetext{
${ }^{1}$ Este artigo faz parte do projeto de pesquisa: Sobre a função didática e os usos (meta) argumentativos do termo "acessórios" nas sentenças pronunciadas pela Suprema Corte de Justiça de Buenos Aires (SCBA). Consejo Nacional de Investigaciones Científicas y Técnicas (CONICET); período $2014-2017$.
} 
EID\&A - Revista Eletrônica de Estudos Integrados em Discurso e Argumentação, Ilhéus, n. 14, jul/dez.2017.

Também pretendemos demonstrar de que forma este máximo organismo do Poder Judicial de Buenos Aires se converte em um instrumento não apenas de normalização ou estandardização de normas jurídicas ao "dizer o direito", mas também de normas linguístico-jurídicas, ao dizer "como o Direito deve ser dito"2.

\section{Questões e argumentos: sobre as razões acessórias}

O civil law é um sistema jurídico no qual, como acontece na Argentina, os juízes devem inferir a solução do caso a partir de princípios e normas gerais e abstratas formuladas a priori (constituição, tratados internacionais, códigos, leis, etc.). Neste sistema jurídico, como regra geral, os precedentes judiciais que formam o que se conhece como "jurisprudência" - não são juridicamente obrigatórios, a menos que a norma jurídica estabeleça desta forma. Mesmo que não sejam obrigatórios, devido à falta de uma norma jurídica que determine que sejam, alguns destes precedentes são considerados ou "sentidos" como se fossem, seja pelo poder de persuasão que resulta da hierarquia do organismo judicial (por exemplo, as sentenças da Corte Suprema da Nação, na Argentina - de agora em diante $(S N A)^{3}$, seja por uma necessidade de coerência do organismo judicial que o leva a não se separar, sem novos fundamentos, das soluções que foram dadas a caso semelhantes.

Excepcionalmente na Argentina, os precedentes são juridicamente obrigatórios. No entanto, as sentenças da SCBA - que são chamadas "doutrina legal" - constituem precedentes cujo acatamento é obrigatório para todos os tribunais inferiores desta província, tal como aparece no art. 279 do Código de Processo Civil e Comercial da Província de Buenos Aires - daqui em diante CPCC Bs. As. ${ }^{4}$. Deste modo, as sentenças da SCBA terão o maior poder institucional, jurídico e acadêmico em casos futuros, estabelecendo

\footnotetext{
2 Esclarecemos que uma primeira versão deste trabalho, "Omisión de argumento esencial y uso meta-argumentativo evaluativo de los argumentos a mayor abundamiento" Omissão de argumento esencial e uso meta-argumentativo avaliativo dos argumentos acessórios), foi apresentada no XV Congreso Nacional de la Sociedad Argentina de Lingüística, na Universidad Nacional del Sur, Bahía Blanca, no período de 11 a 14 de maio de 2016.

${ }^{3}$ Finalmente, se o critério da CSNA não fosse seguido, o organismo judicial que não seguisse ficaria exposto à revogação da sua sentença, caso seja recorrida diante desta Corte.

${ }^{4}$ Neste sentido, "os pronunciamentos da Corte Suprema de Justiça da Nação, assim como outros tribunais, não constituem a 'doutrina legal' a qual se refere o art. 279 do Código Processual Civil e Comercial” (SCBA LP RI 117796 I 25/11/2015 Caso: Giménez, Oscar Alfredo contra Soler, Hugo Daniel. Despedimento. Magistrados Votantes: Genoud-Kogan-Pettigiani-de Lázzari; SCBA LP RI 118978 । 18/11/2015 Caso: Larrea, Aníbal Alberto e outros Servicios Royar S.R.L. e outros. Despedimento. Magistrados Votantes: Kogan-Pettigiani-de Lázzari-Soria; SCBA LP RI 119123 I 18/11/2015 Caso: Climiño, Carlos Alberto contra Securitas Argentina S.A. Despedimento. Magistrados Votantes: Kogan-Pettigiani-de Lázzari-Soria; etc. Disponíveis em: http://juba.scba.gov.ar
} 
EID\&A - Revista Eletrônica de Estudos Integrados em Discurso e Argumentação, Ilhéus, n. 14, jul/dez.2017.

potencial jurisprudência que se instaurará como norma/modelo para o resto dos tribunais provinciais.

Por outra parte, no nosso sistema jurídico, cabe diferenciar entre "pedidos", "questão" e "argumento" (SOSA \& CUCATTO, 2014; SOSA, 2015). O "pedido" é a afirmação de um direito e a petição da sua tutela jurisdicional. Quem afirma ser titular de um direito deve expor os fatos dos quais pode ser extraído o direito afirmado, em conformidade com os princípios e normas jurídicas aplicáveis. Para resolver sobre o pedido, para dar ou não um lugar a ela, o organismo jurisdicional deve responder dentro dos limites demarcados no pedido, isto é o que se denomina "princípio de congruência decisória" e, para isso, deve dar resposta ordenada a diferentes "questões" utilizando "argumentos".

No entanto, o que se entende por "questão"? Quando diante de um tópico factual, probatório ou jurídico existir uma encruzilhada do tipo "ser ou não ser", há então uma "questão". Temos uma questão de fato quando se trata de determinar se um fato com suas particulares circunstâncias de pessoas, tempo, lugar, modo, etc., existiu ou não existiu. Há uma questão de prova quando se considera se tal ou qual meio de prova pode ser admitido ou não. Estamos na presença de uma questão de direito quando se discorre se uma norma jurídica é aplicável ou não é aplicável, se é constitucional ou não é constitucional, etc.

Para responder uma questão é preciso tomar partido por um dos dois termos da mencionada questão: algo não pode ser e não ser ao mesmo tempo. O fato existiu ou não existiu, o meio de prova pode ser atendido ou não atendido, a norma jurídica é válida ou não é válida. As questões são perguntas totais, já que só admitem ser respondidas afirmativa ou negativamente. Neste sentido, os juízes devem oferecer "argumentos" razões, motivos ou fundamentos- pelos quais se inclinam em direção a um ou outro termo de qualquer questão que devam enfrentar.

Além disso, as questões, que devem ser abordadas para dar resposta adequada a um pedido, têm que ser detectadas, ordenadas e tratadas adequadamente. Uma questão não tratada é "omitida" quando, devendo ser tratada para dar uma resposta adequada ao pedido, não é; ao invés disso, uma questão é "deslocada" quando não deve ser tratada porque com o tratamento de uma questão anterior ao pedido ficou adequadamente 
EID\&A - Revista Eletrônica de Estudos Integrados em Discurso e Argumentação, Ilhéus, n. 14, jul/dez.2017.

respondida (CUCATTO \& SOSA, 2016a e b) ${ }^{5}$. Omitir o tratamento expresso de uma questão é decidir "pelo não" de modo tácito e infundado e, consequentemente, de modo inválido ${ }^{6}$; essa decisão sobre a questão, assim tomada, terá que levar a certa decisão final sobre o pedido.

Se a decisão "pelo sim" de uma questão, expressa e fundada e consequentemente, válida, pudesse ter levado a uma decisão diferente sobre o pedido, a questão omitida é "essencial” (CUCATTO \& SOSA, 2016b) 7 . Em relação a qualquer questão, essencial ou não, já mencionamos que o organismo judicial deve dar expressamente as razões pelas quais de inclina para um ou para outro dos seus termos, por que sim ou por que não, essas são as alternativas possíveis. Argumentar é dar os argumentos, razões, motivos ou fundamentos que sustentam um ponto de vista (SOSA \& CUCATTO, 2014), e tudo isso para produzir um efeito persuasivo (PERELMAN \& OLBRECHTS-TYTECA, 1958).

No entanto, já no território das razões, fundamentos ou argumentos, termina que não todos eles possuem a mesma entidade, de maneira que a decisão de uma questão, pelo sim ou pelo não, pode estar sustentada por argumentos de diferente peso persuasivo: os argumentos que por si só sustentam a decisão da questão podem ser denominados essenciais ou dirimentes - e formam o holding ou ratio decidenci -, enquanto que os argumentos usados como complemento, quando outros já sustentam a decisão, podem ser chamados argumentos acessórios ou obiter dicta (BERNAL PULIDO, 2005; MATTILA, 2006; CASTILLO ALVA, 2008; FRONDIZI, 1994; GASCÓN ABELLÁN, 2004; PEYRANO, 1994, 2000; ROJAS AMANDI, 2012; VALLET DE GOYTISOLO, 2009) ${ }^{8}$; e estes últimos podem resultar de duas situações diferentes: a- são aqueles que, seja qual for a sua entidade, servem

\footnotetext{
5 Por exemplo, se um tribunal declara a inadmissibilidade do recurso, por exemplo, por extemporâneo, "desloca" a necessidade de responder jurisdicionalmente outras questões. Agora, se o juiz argumenta a modo acessório, poderia continuar analisando questões de admissibilidade, isto PE, poderia responder a "questões deslocadas" concernentes de que se o recurso utilizado é ou não uma via impugnativa idônea - concluindo que não é -, de que se o recorrente é ou não parte - concluindo que não é-, etc., reforçando sua conclusão no sentido de que o recurso é admissível.

${ }^{6}$ Está estabelecido desta forma nos artigos 34.4, 161 incisos 1 e 2, 163 incisos 5 e 6 e 169 parágrafos $1^{\circ}$ e $2^{\circ}$, CPCC Nação e CPCC Bs.As.

7 Sobre o conceito de “questão esencial", consultar TESSONE (2005); CUCATTO e SOSA (2016b); também, SCBA: Acordo.119557, I 18/03/2015; Acordo.119471 I 04/03/2015; Acordo. 119485, 04/03/2015; Acordo. 119399 I 29/12/2014; Acordo.119026 I 23/12/2014; Acordo. 119465 I 18/03/2015; Acordo. 119571 I 04/03/2015, entre outros. Acordos disponíveis em: http://juba.scba.gov.ar

${ }^{8}$ Os desenvolvimentos teóricos dos autores anteriormente mencionados correspondem ao âmbito da "doutrina jurídica", isto é, ao pensamento dos juristas sobre questões jurídicas. Lembremos que a partir dos estudos linguísticos, salvo nossa pesquisa - iniciada no ano de 2012 - não há estudos sobre os argumentos ou as expressões conectivas acessórias ou obiter dicta.
} 
EID\&A - Revista Eletrônica de Estudos Integrados em Discurso e Argumentação, Ilhéus, n. 14, jul/dez.2017.

para sustentar uma questão deslocada; b- são os que, de entidade menor, e com igual orientação argumentativa que as razões dirimentes, contribuem para sustentar a decisão em torno a uma questão (CUCATTO, 2015; SOSA \& CUCATTO, 2014).

Na província de Buenos Aires, se o organismo judicial, ao emitir sua sentença e decidir sobre um pedido, omite o tratamento expresso de uma questão essencial, isso habilita o questionamento da sentença através de um recurso de nulidade - ordinário ou extraordinário, segundo corresponda pela instância de que se trate-. No entanto, se o organismo judicial, ao emitir sua sentença e ao decidir sobre um pedido, não omite o tratamento expresso de nenhuma questão, e se, ao tratar as diferentes questões, utiliza para cada uma diferentes argumentos - algum(s) dirimente(s), outro(s) acessório -, o recorrente incorre na omissão de questionamento de argumento essencial quando, ao atacar a sentença, não procura refutar o ou os argumento(s) dirimente(s) utilizados no sustento da decisão das diferentes questões e, em definitiva, no sustento da decisão final sobre o pedido. Enquanto que a omissão do tratamento expresso de uma questão essencial pode conduzir à nulidade de uma sentença, a omissão ou questionamento expresso de algum argumento essencial pode conduzir à confirmação dessa sentença através da recusa do recurso contra ela (CUCATTO \& SOSA, 2016a, 2016b).

Como já mencionamos, é o propósito deste artigo descrever e explicar, a partir de dois casos extraídos de um corpus de sentenças emitidas pela SCBA, de que forma este máximo tribunal essencial, através do que denominamos uso meta-argumentativo avaliativo de acessório (CUCATTO, 2016a), se encarrega de recusar os recursos nos quais se objetam as razões acessórias, mas não os argumentos essenciais que sustentam a decisão recorrida. Para proceder desta maneira, este máximo tribunal provincial realiza uma função didática, ao mesmo tempo em que indica aos recorrentes como diferenciar entre os argumentos dirimentes dos que não são, como devem ser utilizados os argumentos não dirimentes e como deve ser idoneamente atacada uma decisão judicial que contém argumentos dirimentes e outros que não são. Deste modo, o superior tribunal vai além da sua estrita função jurisdicional decisória, pois instrui os operadores judiciais sobre como argumentar. 
EID\&A - Revista Eletrônica de Estudos Integrados em Discurso e Argumentação, Ilhéus, n. 14, jul/dez.2017.

2. Uso meta-argumentativo avaliativo das razões acessórias: valorizar, instruir e normatizar

Apesar de que nesta ocasião nos deteremos no uso meta-argumentativo avaliativo das razões acessórias, desejamos destacar que em nossa pesquisa ${ }^{9}$ detectamos dois usos meta-argumentativos diferentes e complementários destes argumentos não dirimentes (CUCATTO, 2016a):

- uso meta-argumentativo avaliativo das razões acessórias: quando a SCBA examina e avalia as razões acessórias utilizadas na sentença impugnada, à luz do questionamento realizado pelos recorrentes ${ }^{10}$;

- uso meta-argumentativo exegético das razões acessórias: quando a SCBA tenta fazer saber "o que são" e "qual é a função" dos argumentos acessórios, através da identificação das suas características prototípicas; ${ }^{11}$ a SCBA define e caracteriza estes fundamentos não decisórios ou obiter dicta a fim de diferenciá-los dos fundamentos essenciais ou dirimentes do caso.

A partir da análise do nosso corpus, sobre uma base de 50 sentenças (100\%) emitidas pela SCBA, durante o período compreendido entre os anos 2000 e 2015 - com um total de 86 ocorrências da expressão acessório ${ }^{12}$-, foi possível advertir que este máximo tribunal parece preferir o uso metaargumentativo das razões acessórias e não, em troca, o uso desta expressão conectiva na hora de fundamentar suas próprias sentenças - que denominamos, em uma primeira etapa da pesquisa, uso argumentativo das razões acessórias ${ }^{13}$. De fato, no nosso corpus foi possível evidenciar que, das 50 sentenças (100\%) analisadas, a SCBA realiza um uso meta-argumentativo das razões acessórias em 43 sentenças (86\%) e apenas um uso argumentativo das razões acessórias em 7 sentenças (14\%).

\footnotetext{
${ }^{9}$ Ver nota 1

${ }^{10}$ Deve-se esclarecer que os ministros deste máximo tribunal, ao realizar esta tarefa, mostraram, em ocasiões, dissidências.

${ }^{11}$ Quando falamos em "características prototípicas", referimo-nos às propriedades ou atributos característicos que permitem estabelecer o enquadramento na categoria "argumento acessório". Para mais informações, consultar a nota 14.

12 Estas sentenças foram obtidas na seção "Sumários e sentenças JUBA (busca ampliada)" correspondente à página da SCBA. Para a definição de nosso corpus de pesquisa foram utilizados os seguintes critérios de busca: termo acessórios; campos: matéria, vozes, $\mathrm{n}^{\circ}$ de causa, caso, texto do sumário. Última consulta: 1/3/16. Precedentes disponíveis em: http://www.scba.gov.ar/portada/default2014.asp .

13 Entendemos por "uso argumentativo das razões acessórias" quando a SCBA utiliza estes fundamentos colaterais nas suas sentenças, exibindo um modelo "prototípico" de uso "correto" (CUCATTO, 2016a).
} 
EID\&A - Revista Eletrônica de Estudos Integrados em Discurso e Argumentação, Ilhéus, n. 14, jul/dez.2017.

Por outro lado, dentro dos usos meta-argumentativo das razões acessórias, pode-se constatar que existe uma tendência a combinar os usos meta-argumentativos avaliativos e exegéticos. Neste respeito, pode-se diferenciar, por um lado, ambos os usos meta-argumentativo combinados em 31 das sentenças (62\%) analisadas, e, por outro, um uso meta-argumentativo avaliativo puro - isto é, não combinado ao uso meta-argumentativo - em 12 sentenças (24\%). Além disso, pode-se observar que a SCBA, quando examina e avalia o uso destes argumentos acessórios por parte de um tribunal inferior, e o questionamento destes pelo recorrente(s), realiza uma função didática, dado que instrui aos profissionais de Direito -destinatários de suas sentençassobre qual "deve ser" o uso "correto" destas razões de apoio à decisão (CUCATTO, 2014, 2016a, 2016b).

Do mesmo modo, os usos avaliativos de acessórios, desde o ponto de vista da sua esquematicidade argumentativa, tornam possível evidenciar como a SCBA não ignora a existência de certa gradualidade ou continuum ${ }^{14}$ que se manifesta entre duas categorias que a tradição jurídica opõe taxativamente as considerações essenciais ou dirimentes que formam a ratio decidendi e as razões acessórias-. Em trabalhos anteriores (CUCATTO, 2012, 2014; SOSA \& CUCATTO, 2014), desde a teoria dos protótipos (BERLIN \& KEY, 1969; ROSCH 1973, 1977, ROSCH \& LLOYD 1978; HOPPER \& THOMPSON 1980, 1982; LAKOFF \& JOHNSON, 1980; LAKOFF \& TURNER 1989; TAYLOR 1962, 1989; WINTERS, 1990) redefinimos as razões dirimentes e as acessórias como razões “nucleares" e "periféricas", respectivamente, já que se considerou que são categorias graduais e inclusive "reversíveis funcionalmente". Entendemos por "reversibilidade funcional" que um argumento que sob certas circunstâncias pode em um caso funcionar como acessório, sob outras circunstâncias, poderia passar no mesmo caso a funcionar como dirimente ${ }^{15}$. Como é possível

\footnotetext{
${ }^{14}$ Para a Linguística Cognitiva, as categorias não são concebidas como entidades dicotômicas ou binárias, isto é, os elementos do mundo não estão divididos de maneira nítida em "pertencentes à categoria A" e "não pertencentes à categoria A". As categorias são concebidas como entidades graduais ou contínuas nas que há elementos que ocupam a posição central, os denominados protótipos, que compartilham mais informações, propriedades, atributos ou características entre si que outros elementos, que, apesar de pertencerem à categoria, ocupam posições menos centrais, os elementos marginais ou periféricos (IBARRETXE-ANTUÑANO; VALENZUELA, 2012). Por isso preferimos falar de graus de "prototipicidade" ou graus de "esquematicidade argumentativa", para evitar uma perspectiva dicotômica ou binária na hora de categorizar os elementos essenciais e os acessórios.

15 Isto pode acontecer, por exemplo, quando o recorrente ataca com sucesso o argumento dirimente que sustentou a decisão de um juiz de primeiro grau e, então, passam a primeiro plano os argumentos acessórios desse decisório, já que por si só e já sem o protagonismo do argumento dirimente desativado, puderam também sustentar a decisão. Em síntese, entendemos por
} 
EID\&A - Revista Eletrônica de Estudos Integrados em Discurso e Argumentação, Ilhéus, n. 14, jul/dez.2017.

apreciar, esta "reversibilidade funcional", ao não ser considerada na hora de impugnar uma resolução judicial, poderia colocar em risco a eficácia da tarefa dos recorrentes, comprometendo os elementos que fundamentam os seus recursos. Por este motivo, a SCBA, diante deste risco em potencial, ocupa-se, em suas sentenças, de:

1- estabelecer e controlar que os limites que separam os fundamentos decisórios ou "nucleares" das afirmações a mayor abundamiento ou periféricas sejam nítidos e estejam traçados de maneira clara e precisa; e, em consequência,

2- recusar aqueles recursos nos quais estes limites resultem confusos ou estejam mal estabelecidos, isto é, sejam “incorretos" e que, portanto, afetem os elementos que fundamentam dita ferramenta processual.

Agora nos perguntamos: como se relaciona este uso meta-argumentativo avaliativo das razões acessórias com os conceitos de ordenamento, deslocamento e a omissão de argumentos essenciais e acessórios?

A partir da análise do nosso corpus também foi possível constatar que durante esse processo avaliativo antes apresentado, a SCBA desestima aqueles recursos nos quais:

1- o recorrente ataca uma sentença e não "omite" refutar o ou os argumento(s) dirimente(s) ou essencial(ais) utilizados na sustentação da decisão das diferentes questões e, em definitiva, na sustentação da decisão final sobre o pedido;

2- o recorrente se dedica a questionar os argumentos não dirimentes, ou seja, refuta apenas os argumentos acessórios, ignorando ou "deslocando indevidamente" os argumentos dirimentes.

No exemplo a seguir, extraído deste corpus, é possível apreciar de que modo a SCBA desestima a abordagem do acionante - argumento relacionado com uma questão vinculada à "prescrição" -, ao mesmo tempo em que considera que este argumento não foi o argumento essencial na ponderação feita previamente por uma Câmara de Apelação que resultou depois, por maioria, o critério imposto pela sentença. O fundamento relacionado com a prescrição foi uma razão secundária - "um elemento secundário" -, expressada "a modo de acessório" e que não teve incidência na decisão

"reversibilidade funcional" dos argumentos que, conforme sejam o sujeito e as circunstâncias, o argumento acessório pode funcionar como argumento dirimente; isto é, pode passar de uma posição “periférica” -e não dirimente - a uma posição "nuclear” -e dirimente-. 
EID\&A - Revista Eletrônica de Estudos Integrados em Discurso e Argumentação, Ilhéus, n. 14, jul/dez.2017.

adotada; o recorrente "omitiu" refutar o argumento dirimente - "um ponto essencial" - sobre o qual descansava a sentença, ignorando-o e, portanto, não fundamentou corretamente sua reclamação ante a SCBA:

(1) Ora, aqui também não existe razão. Claramente é possível observar que este não foi um ponto essencial na ponderação feita no voto da Magistrada que resultasse depois, por maioria, o critério imposto na sentença. Na realidade, o tema da prescrição foi um elemento secundário, expressado a modo acessório, sobre o qual sucintamente se disse que, no caso, a via do amparo não era a adequada para a sua abordagem. De maneira concreta, não teve incidência na resolução adotada.

B95458. SCBA LP A 68934 S 03/09/2008 Juiz KOGAN (SD). Caso: Llanos Choque, Justino c/Ministério de Economia (Rendas) s/Amparo Província de Buenos Aires (Instituto Provincial de Loteria e Cassinos). Recurso extraordinário de inaplicabilidade de lei

Ao mesmo tempo, em outros precedentes da SCBA procura-se prevenir os acionantes em relação a "virtualidade decisória" das razões acessórias; esta situação ocorre, especialmente, naquelas sentenças nas quais existe certo desacordo entre os próprios ministros deste máximo tribunal no momento de examinar e valorizar o questionamento - correto ou não- que realizam os recorrentes em relação à utilização que destes argumentos fizeram um tribunal inferior ou de primeiro grau:

(2) À questão apresentada, o Senhor Juiz Negri disse:

Assim desmereceu os testemunhos de fs. $780 / 783$ do presente e 58 da causa penal agregada, dado que apenas se referiam a comentários de terceiros sem ter tido conhecimento direto do fato (fs. $1108 \mathrm{vta} /$ /1109).

Depois expressou, de maneira acessória, que sem preconceito do que foi decidido em relação ao nexo causal, a responsabilidade dos demandados se viu desculpada pelo atuar negligente da encarregada circunstancial da menor -sua avó -, que não tomou as precauções normais do caso, transformando a mangueira utilizada para dar banho na menina em perigosa, pela forma como foi utilizada (fs. 1109 e vta.).

Por último, o recurso de inaplicabilidade de lei que não rebate idoneamente o fundamento essencial da sentença (no caso, o referido à inexistência de relação causal), impugnando outro dado acessório resulta insuficiente (conf. Ac. 36.902, sent. de 13-X -1987, em "Acordos e Sentenças", 1987 -IV -232; Ac. 52.492, sent. de $16-V-1995)$.

A respeito, cabe recordar que as considerações da sentença expressas "acessórias", por razões de "lógica Elemental", carecem de caráter decisório (conf. Ac. 80.922, sent. de 19-II-2002).

Pelo exposto e ante a falta de acreditação das infrações legais denunciadas (conf. art. 279, C.P.C.C.), dou meu voto pela negativa.

À questão apresentada, o Senhor Juiz Doutor Hitters disse:

A segunda ressalva se vincula com o exposto pelos ministros preopinantes sobre o embate das considerações que o recurso incorporou a seu decisório "acessórias". 
EID\&A - Revista Eletrônica de Estudos Integrados em Discurso e Argumentação, Ilhéus, n. 14, jul/dez.2017.

Neste sentido, opino que não resultou desacertado que o recorrente dirija também seus agravos em direção a estas reflexões adicionais do a quo, já que de maneira contrária teria deixado subsistente uma peça da parcela que abastecia a recusa do seu pedido.

Afirmou esta Corte que é insuficiente o recurso extraordinário de inaplicabilidade de lei que omite a impugnação de um fundamento que, apesar de ter sido exposto na sentença acessória, tem, no entanto, virtualidade decisória para a recusa do pedido (L. 34.473, sent. de 26 -III -1985). Sendo assim, é correto atacar também esta parcela decisória.

Isto não significa, logicamente, que o resumo deve ter acolhida, nem mesmo que seja necessário aprofundar no tratamento da crítica dos argumentos suplementares da sentença. Se, como é sinalizado no voto precedente, a parte essencial da decisão não foi suficientemente rebatida, é desnecessário aprofundar o embate contra as normas adicionais.

Voto pela negativa.

B27990 - SCBA LP AC 84731 S 07/09/2005 Juiz HITTERS (OP) Caso: R. ,O. R. c/C. E. “. C. e o. s/Danos e prejuízos

Nesta sentença (2), por mais que exista coincidência por parte deste superior tribunal na recusa de um recurso extraordinário de inaplicabilidade de lei por não estar corretamente fundado, isto é, por não refutar o argumento dirimente - "não rebate idoneamente o fundamento essencial da sentença” -, um dos juízes "realiza uma ressalva" afirmando que não é "desacertada" a impugnação de um fundamento que, apesar de exposto na sentença acessória, tem, no entanto, virtualidade decisória para a recusa do pedido. Desta maneira, torna-se evidente que o recorrente deve atacar, para garantir a eficácia da sua tarefa, todos os argumentos -dirimentes e acessórios -, "já que, do contrário, teria deixado subjacente uma peça da parcela que abasteci a recusa do seu pedido". Para a SCBA, as razões acessórias, apresar de não sustentarem um decisório, sim, fundamentam uma sentença e, como consequência, “também” devem ser refutadas pelo recorrente.

Desta forma, a SCBA informa e instrui os recorrentes sobre o modo como se deve confrontar as razões da sentença sob ataque:

a) nunca deve ser omitido o ataque aos argumentos dirimentes ou essenciais e,

b) devem ser enfrentados todos os fundamentos de um decisório: devese contra-argumentar necessariamente primeiro os argumentos dirimentes ou essenciais, e apenas eventualmente depois as afirmações acessórias. 
Deste modo, a SCBA adverte aos recorrentes sobre a "reversibilidade funcional" dos argumentos, como já mencionamos, de acordo com o sujeito e as circunstâncias, o argumento acessório pode funcionar como argumento dirimente - ou vice-versa. Isto demonstra que as categorias "ser argumento dirimente ou essencial" e "ser argumento acessório" são graduais, isto é, não estão opostas taxativamente como a "doutrina jurídica" propõe. Deste modo, por exemplo, pode acontecer que um argumento acessório seja utilizado em um caso futuro semelhante com peso ou papel de decisão diferente; ou ainda pode acontecer que um organismo de revisão deixe sem efeito a decisão baseada na resposta dirimente dada a uma questão - deixe sem efeito o argumento dirimente- e que este organismo tenha que responder às questões para encarregar-se delas- aos argumentos acessórios (SOSA \& CUCATTO, 2014; CUCATTO \& SOSA, 2016a).

Em definitiva, um recorrente, a pesar de nunca poder deixar de atacar as razões que integram o holding ou a ratio decidendi da sentença impugnada, para a eficácia do seu recurso, também não deve deixar de confrontar os argumentos acessórios, já que estes podem chegar a operar ocasionalmente como dirimentes de acordo com a sua reversibilidade funcional.

\section{Considerações finais}

Neste trabalho nos interessou examinar dois precedentes nos quais se manifesta que a SCBA recusa os recursos mediante os quais apenas se atacam os argumentos acessórios, mas se omite questionar os dirimentes, por resultar confusos ou estar mal estabelecidos os limites que separam uns dos outros. De fato, nestes recursos, os acionantes "omitem" refutar os argumentos dirimentes ou essenciais utilizados na sustentação da decisão das diferentes questões e, em definitiva, na sustentação da decisão final sobre o pedido, e apenas confrontam os argumentos acessórios. Como consequência, para garantir a eficácia de um recurso e considerando a "virtualidade decisória" dos argumentos acessórios - sua "reversibilidade funcional" -, a SCBA indica aos acionantes eu devem necessariamente refutar todas as razões que cimentam a decisão - sejam dirimentes ou sejam acessórias-. Ora, este máximo tribunal recomenda estrategicamente que seja respeitada uma ordem: primeiro os argumentos que fazem parte da ratio decidendi e, posteriormente, os acessórios. Tudo isto para evitar entrar na contra argumentação dos 
EID\&A - Revista Eletrônica de Estudos Integrados em Discurso e Argumentação, Ilhéus, n. 14, jul/dez.2017.

fundamentos não dirimentes para mais tarde evitar o mesmo em relação aos fundamentos dirimentes ou essenciais.

Como se pode observar, os usos meta-argumentativos avaliativos das razões acessórias -isto é, o exame e a avaliação das razões acessórias realizados pela SCBA, ao resolver sobre os recursos que são de sua competência- permitem constatar de que modo a SCBA exerce uma função didática, já que ensina como diferenciar entre os argumentos que são dirimentes dos que não são, como devem ser utilizados os argumentos não dirimentes e como dever ser idoneamente atacada uma decisão judicial que contém argumentos que são dirimentes e outros que não.

Deste modo, a SCBA vai além da sua estrita função jurisdicional decisória - "dizer o direito" -, pois instrui aos operadores judiciais sobre como argumentar ou, mais especificamente, como um recurso deve ser fundamentado - "como o Direito deve ser dito"-. Em outras palavras, a SCBA se converte em um instrumento não apenas de normalização ou estandardização de normas jurídicas ao "dizer o direito", mas também de normas linguístico-jurídicas ao dizer "como o Direito deve ser dito". Tudo isso adquire notória relevância ao se considerar que este máximo tribunal tem a "última palavra" em aspectos vinculados com os elementos que fundamentam os recursos ante ela apresentados e seus precedentes são instaurados como "norma" a ser seguida - e respeitada - pelos operadores judiciais no território bonaerense.

\section{Referências}

BERLIN, Brent; KAY, Paul. Basic Color Terms: Their Universality and Evolution. Berkeley: University of California Press, 1969.

BERNAL PULIDO, Carlos. El derecho de los derechos. Bogotá: Universidad del Externado de Colombia, 2005.

CASTILLO ALVA, José Luis. El uso de los precedentes judiciales en materia penal como técnica de argumentación racional. Su alcance y valor en el derecho peruano, 2008. Disponivel em: http://perso.unifr.ch/derechopenal/assets/files/articulos/a_20080521_46.pdf. Acesso em: 10 jul. 2017

ARGENTINA. Código Procesal Civil y Comercial de la Nación, 1968. Disponível em: http://servicios.infoleg.gob.ar/infolegInternet/anexos/15000-19999/16547/texact.htm. Acesso em: 10 jul. 2017 
EID\&A - Revista Eletrônica de Estudos Integrados em Discurso e Argumentação, Ilhéus, n. 14, jul/dez.2017.

BUENOS AIRES (Provincia) Código Procesal Civil y Comercial, 1969. Disponível em: http://www.gob.gba.gov.ar/legislacion/legislacion/l-7425.html. Acesso em: 10 jul. 2017

CUCATTO, Mariana. Algunas notas sobre "a mayor abundamiento" en el discurso jurisdiccional”. En: Actas del V Jornadas internacionales de ALFAL. La Plata, Facultad de Humanidades (UNLP), 2012. Disponível em: http://jornadasfilologiaylinguistica.fahce.unlp.edu.ar/v-jornadas/Cucatto.pdf/view.

Acesso em: 10 jul. 2017.

. El rol de la Suprema Corte de Justicia en la normalización lingüística: el caso de las unidades terminológicas 'a mayor abundamiento' - 'obiter dictum'. En: Anais do XVII Congreso Internacional de ALFAL. Brasil: Centro de Ciências Humanas e Letras Universidade Federal da Paraíba, 2014. p. 2486-2496. Disponível em: http://www.mundoalfal.org/CDAnaisXVII/trabalhos/R0734-1.pdf. Acesso em: 10 jul. 2017.

- Estudio sobre los usos argumentativos de la expresión 'a mayor abundamiento' en el discurso jurisdiccional. En: CARRANZA, Isolda; CUCATTO, M. (eds). Temas de discurso público e interacción. Volúmenes temáticos del XIV Congreso Nacional de la Sociedad Argentina de Lingüística. Bahía Blanca: Editorial de la Universidad Nacional del Sur, 2016a. p. 117-140.

. Omisión de argumento esencial y uso meta-argumentativo evaluativo de los argumentos a mayor abundamiento. En: XV Congreso Nacional de la Sociedad Argentina de Lingüística, Universidad Nacional de Bahía Blanca - Sociedad Argentina de Lingüística, 2016b (trabajo presentado en el evento).

; SOSA, Toribio Enrique. Detección, ordenamiento, omisión y desplazamiento de cuestiones. La Ley, Bueno Aires, AÑO LXXX N 4, Tomo LA LEY 2016A, p. 1-4, 07 de enero de 2016a.

; SOSA, Toribio Enrique. Omisión de cuestión esencial y contrafácticos. La Ley, Bueno Aires, AÑO LXXX N 134, Tomo LA LEY 2016D, p. 1-5, 19 de julio de 2016b.

FRONDIZI, Román. La sentencia civil. Tema y variaciones. La Plata: Editora Platense, 1994.

GASCÓN ABELLÁN, Marina. La prueba judicial: valoración racional y motivación. En: Carbonell, Miguel.; Fix -Fierro, Héctor; Vázquez, Rodolfo (comp.). Jueces y Derecho. Problemas Contemporáneos. México: Porrúa, 2004. Disponível em: http://cmapspublic2.ihmc.us/rid=1MYBL04CF-7GoW1S-7L8/Prueba\%20Gascon.pdf.

Acesso em: 10 jul. 2017.

HOPPER, Paul; THOMPSON, Sandra. Transitivity in Grammar and Discourse. Language, n. 56, v. 2, p. 251-299, 1980.

Syntax and Semantics, 15. Studies in transitivity. New York: Academic Press, 1982.

IBARRETXE-ANTUÑANO, Iraide; VALENZUELA, Javier. Lingüística cognitiva. Barcelona: Anthropos, 2012. 
EID\&A - Revista Eletrônica de Estudos Integrados em Discurso e Argumentação, llhéus, n. 14, jul/dez.2017.

LAKOFF, George; JOHNSON, Mark. Metaphors we live by. Chicago: University Press, 1980.

LAKOFF, George; TURNER, Mark. More than Cool Reason: A Field Guide to Poetic Metaphor. Chicago: University Press, 1989.

MATTILA, Heikki. Comparative Legal Linguistics. England: Ashgate, 2006.

PERELMAN, Chaïm; OLBRECHTS-TYTECA, Lucie. Traitè de l'argumentation: La Nouvelle Rhétorique. Bruxelles, Ed. Université de Bruxelles, 1958.

PEYRANO, Jorge. Sobre la función docente de las resoluciones judiciales. Jurisprudencia Argentina, II, 1994, p. 835-836, 1994.

. Los argumentos laterales (a mayor abundamiento, obiter dicta y conjetural) del discurso judicial y la supremacía ideológica de los derechos del consumidor y del usuario. Jurisprudencia Argentina, II, p. 854-857, 2000.

ROJAS AMANDI, Víctor Manuel. La teoría del discurso de Robert Alexy. En: La Ética discursiva en las teorías del derecho de Habermas y Alexy. México: Instituto de Investigaciones Jurídicas - UNAM, 2012. p. 147-275. Disponível em: http://biblio.juridicas.unam.mx/libros/7/3088/5.pdf. Acesso em: 10 jul. 2017.

$\mathrm{ROSCH}$, Eleanor. On the internal structure of perceptual and semantic categories. In: Moore, Timothy (ed). Cognitive Development and the Acquisition of Language. New York: Academic Press, 1973. p. 111-144.

- Human categorization. In: Warren, Neil (ed.). Studies in cross-cultural psychology. New York: Academic Press, 1977. p. 1-49.

ROSCH, Eleanor; LLOYD, Barbara (eds). Cognition and Categorization. Hillsdale: Erlbaum, 1978.

SOSA, Toribio Enrique. Recursos: cuestiones y argumentos. En: Peyrano, J (Ed.). Nuevas herramientas procesales - III. Recursos ordinarios. Santa Fe: Rubinzal Culzoni, 2015. p. 59-69.

; CUCATTO, Mariana. Sobre cuestiones y argumentos. La Ley, Bueno Aires, Tomo LA LEY 2014 -C, LXXVIII N 114, 2014, p. 1-3.

TAYLOR, James. The Behavioral Basis of Perception. New Haven, Connecticut: Yale University Press, 1962.

- Linguistic Categorization. Prototypes in Linguistic Theory. Oxford: Clarendon Press, 1989.

TESSONE, Alberto. Recursos extraordinarios, Juicio de admisibilidad y fundabilidad. El certiorari provincial. Buenos Aires: Abeledo Perrot, 2011. 
EID\&A - Revista Eletrônica de Estudos Integrados em Discurso e Argumentação, Ilhéus, n. 14, jul/dez.2017.

VALLET DE GOYTISOLO, Juan. El razonamiento judicial. Anales, 9, 2009, p.15-28.

WINTERS, Margret. Toward a Theory of Syntactic Prototypes. In: TSOHATZIDIS, Savas (ed.). Meanings and Prototypes. Studies on Linguistic Categorization. London, New York: Routledge, 1990. p. 285-306.

Tradução:

Raquel da Silva Ortega

Docente da Universidade Estadual de Santa Cruz (UESC)

E-mail: rsortega@uesc.br

Forma de citação sugerida:

CUCATTO, Mariana. Omissão de impugnação das razões essenciais e uso metaargumentativo avaliativo das razões acessórias nas sentenças da suprema corte de Buenos Aires. Trad. Raquel da Silva Ortega. EID\&A - Revista Eletrônica de Estudos Integrados em Discurso e Argumentação, Ilhéus, n. 14, p. 101-116, jul/dez.2017.

Recebido em: 31/08/2017

Aprovado em: 25/11/2017 